\begin{abstract}
SebAstián PICARDO GONZÁlEZ
Aspirante a Profesor de Derecho Procesal en la Universidad de la República (Uruguay).

spicardo@guyer.com.uy

ORCID: https://orcid.org/0000-0002-8388-9452
\end{abstract}

ANDRÉS TISCORNIA ALGORTA

Aspirante a Profesor de Derecho Procesal en la Universidad de la República (Uruguay).

andres.tiscornia@dentons.com

ORCID: https://orcid.org/0000-000 I-5563-0489

Recibido: 15/09/2021 - Aceptado: I // I/2021

Para citar este artículo / To reference this article / Para citar este artigo Picardo González, S. y Tiscornia Algorta, A. (2021). LLuz roja para el arbitraje en materia laboral?

Reflexiones sobre la jurisprudencia reciente (con énfasis en el caso "UBER").

Revista de Derecho, 20(40), 15-42. https://doi.org/I 0.47274/DERUM/40.2

\title{
¿Luz roja para el arbitraje en materia laboral? Reflexiones sobre la jurisprudencia reciente (con énfasis en el caso "UBER").
}

Resumen: En este trabajo, nos proponemos analizar -desde una perspectiva procesal- la situación actual del arbitraje en materia laboral en Uruguay. A estos efectos, optamos por realizar un análisis comparativo entre los diferentes fallos jurisprudenciales recientes de algunos órganos jurisdiccionales de Uruguay. Analizamos también, la situación del arbitraje laboral en otras partes del mundo, que entendemos relevantes y de gran utilidad para contextualizar la temática analizada.

Palabras clave: Proceso, arbitraje, derecho laboral, conflictos individuales de trabajo, principios del derecho del trabajo, acceso a la justicia. 


\title{
Drawbacks for arbitration labour matters?
}

\section{Some considerations regarding recent judgements (with emphasis on the "UBER" case).}

\begin{abstract}
In this paper, we propose to analyse -from a procedural perspective- the current situation of labour arbitration in Uruguay. For this purpose, we have chosen to carry out a comparative analysis of the different recent jurisprudential rulings of some courts in Uruguay. We also analyse the situation of labour arbitration in other parts of the world, which we consider relevant and useful to contextualise the subject analysed.
\end{abstract}

Key Words: Procedure, arbitration, labour law, individual labour disputes, principles of labour law, access to justice.

\section{Luz vermelha para arbitragem trabalhista?}

\section{Reflexões sobre jurisprudência recente (com destaque para o caso "UBER").}

\begin{abstract}
Resumo: Neste trabalho nos propomos analisar, desde uma perspectiva processual, a situação atual da arbitragem em matéria trabalhista no Uruguai. Para estes efeitos, optamos por realizar uma análise comparativa entre os diferentes acórdãos jurisprudenciais recentes de alguns órgãos jurisdicionais do Uruguai. Analisamos, também, a situação da arbitragem trabalhista em outras partes do mundo, que entendemos relevantes e de grande utilidade para contextualizar a temática analisada.
\end{abstract}

Palavras-chave: Processo, arbitragem, direito trabalhista, conflitos individuais de trabalho, princípios do direito do trabalho, acesso à justiça. 


\section{Generalidades}

El arbitraje es un método de resolución de conflictos por heterocomposición -privado-. Dentro de los límites inherentes a su calidad de tercero imparcial y de acuerdo a las facultades conferidas por las partes, la función del Tribunal arbitral consiste en resolver las disputas que fueron sometidas a su decisión (en sustitución del Juez, que por principio de "Juez natural" asumiría competencia), emitiendo así, un fallo de carácter vinculante.

En los últimos años, en base a una política de Estado orientada a favorecer la promoción del arbitraje internacional en Uruguay, ${ }^{1}$ el volumen de litigios arbitrales se ha incrementado -en forma moderada- ${ }^{2}$, pese a la negación y/o falta de receptividad que manifiestan actualmente, algunos Tribunales judiciales de nuestro país.

En efecto, los Tribunales judiciales uruguayos, han entendido desde larga data, en función del carácter "alternativo" del arbitraje con relación a la justicia estatal, que; ante la duda sobre la voluntad de las partes, quién debe asumir competencia para conocer en el asunto es el Juez natural y no el árbitro. ${ }^{3}$

Esta ha sido la interpretación predominante respecto al alcance material y personal de la cláusula arbitral, por parte de los Tribunales judiciales de nuestro país. Conforme se verá en lo sucesivo, esta posición es también adoptada por el TAT $1^{\circ}$ en el caso que se comenta (sentencia definitiva de segunda instancia $N^{\circ} 12-111 / 2020$ ). Se advierte la particularidad, de que en el caso, no se discute el alcance de la cláusula arbitral, sino su validez, por tratarse de una cláusula arbitral leonina y la naturaleza "no arbitrable" de la materia en que se enmarca la disputa; "conflictos individuales de trabajo".

Sin embargo, -y no obstante la faceta negativa anunciada-, luego de un largo tiempo sin una regulación de carácter vinculante en materia de arbitraje internacional (debiendo recurrir, por ej. a la Ley Modelo CNUDMI - "Soft law"- para colmar la ausencia de

1 La intención de Uruguay en promover el arbitraje, puede verse en la exposición de motivos del Proyecto de Ley que fuera ulteriormente presentado al parlamento el día 14 de setiembre del año 2015 para la sanción de la LACI. En dicho proyecto, se dejó expresa constancia de que: "nuestro país ha tenido invariablemente una posición favorable a la institución del arbitraje tanto interno como internacional" (cf. p. 3 del Proyecto de Ley) Seguidamente, expresó el Estado Uruguayo en los motivos del Proyecto de Ley que: “...la aprobación de la ley modelo se revela, pues, como necesaria, sería acorde a esa postura tradicional de la República con relación al arbitraje, asumida reiteradamente en el seno de la comunidad internacional y vendría a completar, en línea con los compromisos internacionales antes referidos, nuestra legislación interna, dándose así un apoyo ineludible para el desarrollo del Uruguay como sede de arbitrajes internacionales (cf. p. 4 del proyecto de Ley).

2 Al respecto, compartimos las palabras de los Dres. Santiago Pereira Campos y Valeria Seines, en cuanto a que: "en el contexto latinoamericano, la utilización del arbitraje en Uruguay ha sido y continúa siendo proporcionalmente mucho menor que en países como Brasil, Chile, Colombia o Perú, por ejemplo. Ello se debe, fundamentalmente, al gran prestigio de que goza el Poder Judicial uruguayo y a que, dada la reforma de su sistema de justicia civil (en sentido amplio) operada en 1989, los procesos tienen una duración razonable. Ello ha generado confianza en los operadores a la hora de recurrir al sistema judicial, no obstante, puede advertirse, fundamentalmente en los últimos cinco años, un crecimiento moderado de los casos en que se recurre al arbitraje" (PEREIRA CAMPOS \& SEINES, 2019).

3 Sobre la cuestión, han expresado nuestros Tribunales judiciales que: “Como lo ha sostenido el homólogo de $6^{\circ}$ Turno "cabe partir de un criterio restrictivo de la interpretación de la cláusula arbitral atributiva de competencia. Porque, tratándose de una jurisdicción excepcional que impide el conocimiento de los Tribunales pertenecientes a la Justicia ordinaria, oficial, corresponde admitir el desplazamiento de competencia únicamente en los casos clara y específicamente pactados (T.A.C. $6^{\circ}$ Sent. 165/2009 y otras allí citadas)". Cf. Scia. N ${ }^{\circ}$ 255/2012, TAC $4^{\circ} \mathrm{T}$, Dres. Eduardo Julio TURELL ARAQUISTAIN, Dra. Ana Maria MAGGI SILVA, Dra. Graciela Susana GATTI SANTANA. Véanse también, las sentencias del mismo Tribunal $N^{\circ} 19 / 97$; las sentencias del TAC $2^{\circ} \mathrm{N}^{\mathrm{o}}$ 87/01, LJU 14.348, y la publicada en RUDP 3/89, c. 428, p. 377; sentencia del TAC 5, RUDP 3/89, c. 431, p. 377).

4 Aclaramos desde ya, que no es objeto de este trabajo pronunciarnos sobre el arbitraje en los "conflictos colectivos del trabajo". Sin perjuicio de ello, muchas de las consideraciones efectuadas en el cuerpo de esta obra en cuanto a los conflictos individuales del trabajo, son enteramente trasladables a los primeros. Máxime, teniendo en cuenta que el artículo 472 del CGP (regulación positiva del proceso arbitral doméstico), en cuanto a su ámbito de aplicación material, comprende a "toda contienda individual o colectiva..." y el artículo 57 de la Constitución de la República, en cuanto establece que: "La ley promoverá la organización de sindicatos gremiales, acordándoles franquicias y dictando normas para reconocerles personería jurídica. Promoverá, asimismo, la creación de tribunales de conciliación y Arbitraje." 
regulación. En adelante; la "Ley Modelo"-), el día 13 de julio de 2018, se sancionó la Ley N 19.636 de Arbitraje Comercial Internacional (en adelante "la LACI").

Con la LACI, Uruguay ofrece ahora un marco jurídico adecuado y de carácter vinculante, que regula múltiples aspectos del arbitraje comercial internacional, en armonía con las diversas regulaciones existentes a nivel regional.

De acuerdo al artículo 1.7 de la LACI, se mantiene un criterio amplio del término "comercial", siguiendo la tendencia internacional actual y las disposiciones de la Ley Modelo. La LACI no se limita al estricto concepto de; "acto de comercio" el ingreso de una gran variedad de materias, favoreciendo así el incremento de arbitrajes internacionales con Sede en nuestro país.

La regulación actual -de fuente legal- y el desarrollo global de la actividad comercial internacional, fueron factores determinantes para que el arbitraje en Uruguay, fuera adquiriendo cada vez mayor protagonismo y difusión desde el punto de vista académico y profesional.

El crecimiento del arbitraje en nuestro país, ha generado que se presenten con mayor frecuencia, problemáticas que no son nuevas, pero que motivan diferentes posiciones dogmáticas y jurisprudenciales. Estas posiciones, han variado sucesivamente en función de las distintas circunstancias de tiempo y espacio en las que se suscitan, y -principalmente- por la política procesal asumida por nuestros Tribunales judiciales frente al arbitraje.

El arbitraje en materia laboral, no escapa a esta realidad. La temática que se analiza en este trabajo, ha sido objeto de diversas discusiones dogmáticas y de un constante vaivén jurisprudencial, que no termina por consolidar una posición univoca frente a la posibilidad de acudir al arbitraje para resolver los conflictos individuales de trabajo.

De acuerdo al escenario planteado, en este trabajo nos proponemos analizar la posición adoptada por el TAT $1^{\circ}$, en un caso que ha adquirido una connotación mediática especial, por la identidad de la empresa protagonista del conflicto; Uber B.V. (sociedad de responsabilidad limitada constituida en los Países Bajos) Uber Technologies Uruguay S.A. y Rasier Operations B.V. (en adelante: “UBER”).

Asimismo, analizamos los argumentos del TAT $1^{\circ}$ de acuerdo con el ordenamiento jurídico uruguayo y -especialmente-, a la luz de la posición de los Ministros integrantes de la Suprema Corte de Justicia (en adelante: "SCJ"), en la sentencia No 596 dictada en el año 2017. Adelantamos desde ya que, la resolución de la SCJ -según veremos y sin perjuicio de la posición de los Ministros discordes-, es diametralmente opuesta a la decisión emitida por el TAT $1^{\circ}$ en el caso comentado.

\section{La "materia arbitrable" bajo la ley procesal uruguaya}

De acuerdo al ordenamiento jurídico uruguayo, el proceso arbitral de carácter doméstico, se encuentra regulado en las disposiciones de los artículos 472 y siguientes del 
Título VIII del Código General del Proceso (“CGP”). El arbitraje comercial internacional en cambio, se regula actualmente por la LACI.

Empero, cuando intentamos definir el concepto de "materia arbitrable" de acuerdo con el ordenamiento jurídico uruguayo, debemos necesariamente, contemplar las disposiciones legales consagradas expresamente en nuestro C.G.P. Ello, sin perjuicio de lo establecido en el art. 1.7 de la LACI, en cuanto a su alcance material de aplicación, ya comentado al comienzo.

En este sentido, de la conjugación armoniosa de los artículos 472 y 475 del CGP, surge cuál es el criterio que el legislador uruguayo previó para que una materia sea o no arbitrable.

En efecto, el artículo 472 del CGP regula la cuestión en forma positiva y en términos amplios, estableciendo que: "toda contienda individual o colectiva podrá ser sometida por las partes a resolución de un tribunal arbitral, salvo expresa disposición legal en contrario" (el destacado nos corresponde).

A su turno, el art.476 del CGP establece una regulación en forma negativa y en sentido más estricto, indicando que: "no pueden someterse a proceso arbitral las cuestiones respecto a las cuales está prohibida la transacción"6 (el destacado nos corresponde). El tenor literal de ambos textos legales es claro.

Los conflictos intersubjetivos que se presentan en el plano de la realidad social y que, por naturaleza, pueden ser disueltos -extrajudicialmente- o resueltos -judicialmente-, por los interesados principales realizándose recíprocas concesiones, también admitirán su resolución -en el plano de la realidad jurídica- mediante arbitraje. Naturalmente, podrá un Tribunal arbitral conocer sobre la cuestión de fondo planteada, siempre y cuando las partes así lo hayan estipulado en ejercicio de su autonomía de la voluntad.

En otras palabras, el C.G.P. regula la arbitrabilidad objetiva, con carácter general de las materias que pueden ser sometidas a arbitraje.

Sobre la cuestión, se ha dicho en doctrina que, en principio, se puede someter todo tipo de disputas tanto a los tribunales arbitrales como a los estatales, siempre que la materia no sea indisponible. Sin embargo, como advierten algunos autores, es frecuente que los diversos ordenamientos jurídicos reserven la resolución de cierto tipo de disputas, cuya materia es considerada especialmente "sensible", a los tribunales estatales (Olivera García \& Jimenez de Aréchaga, 2000, págs. 6-30).

A nuestro juicio, el concepto de "sensibilidad" a que refiere con acierto la doctrina y que es utilizado en otros ordenamientos jurídicos, es en puridad, una cuestión de apreciación subjetiva que se contrapone con cualquier definición y sentido de seguridad y certeza jurídica. Por este motivo, y en virtud de que nuestra ley procesal contiene dos disposiciones con un alcance claramente definido, preferimos referirnos a la materia "no arbitrable", realizando en principio, una interpretación gramatical de las normas en

6 Para determinar el alcance del término "transacción” debemos acudir, conforme a las pautas interpretativas del Código Civil, a lo previsto en el artículo 2147 y siguientes de dicho cuerpo legal, que establece que: "La transacción es un contrato por el cual, haciéndose recíprocas concesiones, terminan los contrayentes un litigio pendiente o precaven un litigio eventual. Cualquiera que sea la entidad del objeto u objetos sobre que verse la transacción, se requiere para su validez que conste por acto judicial o por escritura pública o privada". 
cuestión, evitando así extender su alcance material u objetivo a conceptos que arrojan mayor ambigüedad.

En este sentido, -para nosotros y de acuerdo con nuestro ordenamiento jurídico-, será materia "no arbitrable", únicamente aquella que no sea susceptible de transacción.

Así, las contiendas de carácter social -en general, (con la salvedad de algunas causas que, si admiten transacción, por ej. algunas causas de Derecho de Familia "patrimonial" $\mathrm{y}$ la que se comenta en este trabajo) y aquellas de carácter infraccional y penal, no adquieren la calidad de "materia arbitrable" por tratarse de cuestiones indisponibles. En estos casos, aun cuando las partes decidan de común acuerdo someter sus disputas a la jurisdicción arbitral, la cláusula arbitral será nula, y todo fallo arbitral que resuelva una disputa de esta naturaleza podrá ser anulado.

Realizada esta precisión en cuanto al concepto de "materia arbitrable" bajo el ordenamiento jurídico uruguayo, veamos a continuación, que ocurre con el arbitraje en materia de Derecho Laboral.

Adelantamos desde ya, que la admisibilidad del arbitraje en material laboral en Uruguay ha sido -desde siempre-, objeto de múltiples obstáculos, que fueran ya comentados a nivel dogmático y que, al parecer, permanecen al día de hoy. En este sentido, suscribimos las palabras del Prof. Santiago Pereira Campos, en cuanto a que: "respecto a la hipótesis del arbitraje facultativo existe una marcada resistencia en nuestro país, y en cuanto al arbitraje obligatorio, siempre ha merecido la oposición, no sólo de los sindicatos que lo consideran una forma de limitación inconstitucional del derecho de huelga, sino también de los empleadores que -por otros motivos- desconfían del fallo de un tercero" (Pereira Campos, 1995, pág. 414).

\section{3. ¿Cuál es el panorama del arbitraje laboral a nivel internacional?}

Conforme señala el Prof. PEREIRA CAMPOS, S. -en cita a MERINO, S.-, "el arbitraje laboral..., se halla fuertemente limitado por condicionamientos sociopolíticos lo que, a su vez, ha originado una gran variedad de soluciones en los distintos ordenamientos". (Pereira Campos, 1995, pág. 414).

Por ello, en este apartado comenzamos por destacar cuál es la situación del arbitraje en materia laboral en otras partes del mundo y particularmente en la región.

\footnotetext{
7 Al respecto, se ha dicho que: "la transacción en materia laboral es muy común en nuestro país en los acuerdos que se celebran en el Ministerio de Trabajo y, generalmente, dentro del acto conciliatorio extrajudicial o judicial está contenida una transacción" (Plá Rodríguez, 1987).

8 Sobre este punto, se ha dicho en cuanto al posibilidad de acudir al arbitraje en materia de familia, que: “...resulta necesario desde el principio efectuar una distinción entre lo que es Derecho de Familia personal por un lado y el Derecho de Familia patrimonial por el otro (...) De esta forma, en base a dicha distinción, se observa que en la mayoría de los aspectos que refieren al Derecho de Familia personal nos vamos a encontrar mayormente ante situaciones de materia no arbitrable, dado que la disponibilidad de derechos es menor. Indisponibilidad que tiene como fundamento los derechos que se buscan tutelar. No obstante, lo anterior no significa que en lo referente al Derecho de Familia patrimonial se pueda generalizar en relación con la posibilidad de encontrarnos ante materia arbitrable puesto que no puede establecerse como regla general. Lo que, si podemos afirmar, es que -sin perjuicio de las circunstancias del caso concreto- en materia de Derecho de Familia patrimonial, los conflictos que se generen serán más proclives a ser sometidos a arbitraje" (Theoduloz Duarte, 2019, pág. 156).
} 


\subsection{La situación del arbitraje laboral en algunos países de Latinoamérica}

En la República Argentina el legislador previó desde el año 1996 una regulación específica del arbitraje en materia laboral en el Título IX de la Ley N²4.635 (Ley de Procedimiento laboral). Concretamente, en su artículo 28, reguló la posibilidad de someter los "reclamos individuales" de trabajo a la decisión de un tribunal arbitral. ${ }^{10}$ Los artículos sucesivos, regulan el contenido del compromiso arbitral y demás aspectos procesales del arbitraje. Sin embargo, según lo indica la doctrina, el arbitraje laboral no tuvo éxito en aquel país.

En razón de las deficiencias que presenta el sistema judicial de aquel país, la doctrina entendió necesario fomentar otros mecanismos para resolver los conflictos de esta naturaleza, dentro de los cuales se encuentra, naturalmente, el arbitraje. Lejos de limitar las garantías y protecciones del trabajador, -para algunos autores-, el arbitraje se presenta como una herramienta adecuada y acorde a sus intereses. El objetivo entonces, debería ser elaborar un sistema arbitral apropiado para los trabajadores en vez de abandonar el empleo de este método (Fernandez Arroyo \& Vetulli, 2020, pág. 1).

En la República del Perú, la Ley No 29.497 ("Nueva Ley Procesal del Trabajo" -en adelante; "NLPT") regula de manera expresa la posibilidad de resolver las disputas laborales mediante mecanismos alternativos de resolución de conflictos, entre los cuales se encuentra el arbitraje.

Un aspecto a destacar, es que el proceso arbitral resulta admisible -según la sexta disposición complementaria de la NLPT- cuando; (i) "el convenio arbitral se inserte a la conclusión de la relación laboral"; y (ii) "adicionalmente, la remuneración mensual percibida sea, o haya sido, superior a las setenta (70) Unidades de Referencia Procesal". Así entonces, será posible acudir a arbitraje, siempre que el trabajador perciba ingresos superiores a lo previsto en la norma y se pacte resolver las disputas ante arbitraje. En caso contrario, aun cuando se introduzca una cláusula arbitral en el contrato de trabajo, será la justicia ordinaria quien deberá entender en el asunto (Higa García, 2016, págs. 306-309).

\subsection{La posición de la Suprema Corte de Justicia de Canadá}

En la sentencia No38534 dictada con fecha 26 de junio del corriente año (2020), la Suprema Corte de Justicia de Canadá se pronunció sobre la validez de la cláusula arbitral introducida en el contrato celebrado entre la empresa UBER y un trabajador. ${ }^{11}$

Según lo estipulado en el contrato, cualquier disputa que surgiera entre las partes, sería resuelta mediante arbitraje con Sede en Holanda.

En el caso, UBER opuso la excepción de falta jurisdicción que fuera finalmente acogida por el Tribunal en primera instancia. Ello, bajo el fundamento de que en virtud del principio kompetenz-kompetenz, es el propio Tribunal arbitral quien debe resolver acerca de su propia competencia. 
No obstante, en segunda instancia sostuvo el Tribunal de Apelaciones que la disputa podía ser planteada ante las Cortes de Ontario, y que no es posible acudir al arbitraje para resolver el asunto, en atención a la desigualdad real de las partes y los altos costos del arbitraje (según lo indicado en la sentencia, los mismos ascenderían a USD 14.500 sumado a tributos legales y costos del proceso).

La sentencia dictada por el Tribunal de segunda instancia fue recurrida por UBER. La Suprema Corte de Justicia de Canadá finalmente resolvió -en base al criterio empleado en el caso Dell Computer Corp. v. Union des consommateurs [2007] y Seidel v. TELUS Communications Inc. [2011]- que la cláusula arbitral es nula por haber sido introducida en el contrato sin que el actor (trabajador) tuviera poder real de negociación.

Asimismo, sin desconocer el principio Kompetenz-Kompetenz, la Suprema Corte de Justicia de Canadá sostuvo que, pretender en estos casos hacer valer la cláusula arbitral -a pesar de los obstáculos materiales a los cuales debe enfrentarse el trabajador, como la onerosidad del proceso- conllevaría a una denegación de justicia. Vale destacar, que los costos del arbitraje eran similares a los ingresos anuales del trabajador y desproporcionados con el reclamo pretendido.

Sin embargo, advierte la Suprema Corte de Justicia de Canadá, que previamente el trabajador deberá acreditar que efectivamente no tiene los recursos suficientes para plantear su demanda ante un Tribunal arbitral y costear los honorarios, tasas y otros gastos correspondientes al arbitraje.

Se agrega en la sentencia que, según el contrato, el trabajador únicamente podría hacer valer sus derechos mediante arbitraje. Sin embargo, por razones económicas el acceso a este mecanismo de resolución de disputas se encuentra fuera de su alcance. Así entonces, sus derechos derivados del contrato celebrado con UBER resultarían inexistentes debido a la imposibilidad material de hacer valerlos en la justicia oficial ordinaria.

En definitiva, la onerosidad del arbitraje, la falta de poder de negociación del trabajador y la imposibilidad material de hacer valer sus derechos en la justicia oficial, por haber suscrito una cláusula arbitral leonina, motivó a que la Suprema Corte de Justicia de Canadá declarara nula la cláusula arbitral por ser contraria a las políticas públicas de aquel país.

\subsection{Breves referencias a la situación del arbitraje laboral en algunos países de Europa}

En algunos países de Europa, existe una tendencia negativa respecto a la aceptación del arbitraje para resolver los conflictos individuales de trabajo. A modo de ejemplo, la Corte de Casación francesa se ha pronunciado sobre la cuestión, señalando que son nulos los convenios arbitrales que atribuyen jurisdicción a un Tribunal arbitral, en virtud de la inarbitrabilidad de la materia laboral. ${ }^{12}$ En sentido similar, se han pronunciado algunos Tribunales estatales de Suiza (Heredia Cervantes, 2010, pág. 2). 
En España, el legislador excluyó expresamente del ámbito de aplicación de la Ley N60/2013 (Ley de Arbitraje de España), el arbitraje en materia laboral. ${ }^{13}$ Sobre el particular se ha dicho en doctrina que: “(...) existen dos razones que han justificado dicha exclusión; de un lado, la especialidad de la materia laboral esencialmente en todo lo que refiere a los derechos que la legislación laboral otorga a los trabajadores respecto del empleador y, de otro, la necesidad que las resoluciones a los conflictos individuales y colectivos sean, en la medida de lo posible, lo más rápidas y ejecutivas" (Galindo Gil, pág. 10).

\section{E1 precedente de la suprema corte de justicia uruguaya}

Contrariamente a lo expresado por el TAT $1^{\circ}$ en el fallo jurisprudencial que se comenta, la SCJ en la sentencia № 596/2017, confirmó la arbitrabilidad objetiva de los conflictos individuales de trabajo.

Los Sres. Ministros Jorge Chediak, Felipe Hounie y Elena Martínez, que conformaron la mayoría debidamente integrada de la SCJ, formularon los argumentos que motivaron el fallo, en base a la regulación general establecida en el CGP (cf. arts. 472, 473.1, 475.1 y 476 del CGP).

De acuerdo a dicho cuerpo legal, la SCJ -en mayoría- expresó que: "el proceso arbitral resulta admisible en "... toda contienda individual o colectiva..." (art. 472), pudiéndose pactar la cláusula arbitral en cualquier "... contrato o en acto posterior..." (art. 473) y únicamente se encuentra vedada la posibilidad de recurrir al proceso arbitral cuando se trata de cuestiones respecto a las cuales "... está prohibida la transacción" (art. 476) o exista "... expresa disposición legal en contrario..." (art. 472).

Según la posición de la SCJ, será inadmisible el arbitraje únicamente en las siguientes hipótesis: (i) cuando el asunto no admite transacción; o (ii) cuando existe expresa disposición legal en contrario.

Al respecto, en comentario a dicha sentencia, señalaron los Dres. Olivera y Saravia que, a juicio de la SCJ "en el caso de conflictos individuales de trabajo, no se verifica ninguno de los supuestos en los cuales no es posible establecer una cláusula compromisoria" (Olivera Rangel \& Saravia, 2018, pág. 97). ${ }^{14}$

En otro orden, en cuanto a los principios especiales del Derecho del Trabajo y en particular, el Derecho Procesal Laboral, la SCJ expresó que: "el carácter imperativo, la indisponibilidad y los principios que gobiernan el derecho del trabajo, tampoco resulta incompatible con el proceso arbitral", regulado en los artículos 1, 30 y 31 de la Ley $\mathrm{N}^{\circ} 18.572$.

La SCJ también analizó la relación del arbitraje con el principio de irrenunciabilidad, concluyendo que, el arbitraje no implica la renuncia del trabajador a la tutela de las

13 El artículo 1.4 de la Ley de Arbitraje española, establece, bajo el acápite "ámbito de aplicación", lo siguiente: "Quedan excluidos del ámbito de aplicación de esta ley los arbitrajes laborales".

14 Sobre el particular, señala el Prof. Garmendia, M. que: "Tal aserto se ve robustecido a partir de que el Derecho del Trabajo, como disciplina jurídica con un amplio componente de negociación, no ha descartado la pertinencia de los mecanismos alternativos para solucionar los conflictos de derecho, aun cuando, para algunos autores, habría de acotar su alcance a los límites que resulten compatibles con su propia esencia protectora" (Garmendia, 1999, pág. 599). 
normas laborales y a los principios -sustantivos y procesales- aplicables, en tanto "los árbitros estarán indefectiblemente sujetos a dicho marco legal".

Adicionalmente, señala la SCJ que no existe disposición legal alguna que prohíba someter los conflictos individuales de trabajo a la decisión de un tribunal arbitral. Para la SCJ, el artículo 2 de la Ley $N^{\circ} 18.572$ establece cuales son los Tribunales competentes, pero ello no implica una intención del legislador de impedir el arbitraje. Se trata de una norma atributiva de competencia, cuya única finalidad es distribuir la competencia de los tribunales judiciales. Empero, ello no es óbice para someter el conflicto a la decisión de un tribunal arbitral.

Finalmente, sobre la imposibilidad de acudir al arbitraje en virtud de que la ley $\mathrm{N}^{\circ}$ 18.572 -de carácter especial-no lo prevé expresamente como un mecanismo de resolución de "conflictos individuales de trabajo", a criterio de la SCJ, este argumento es más efectista que jurídicamente acertado (Olivera Rangel \& Saravia, 2018).

\section{El caso "UBER", tramitado ante el juzgado letrado de trabajo de la capital de $6^{\circ}$ turno. ${ }^{15}$}

El caso se enmarca en un conflicto individual de trabajo tramitado -en primera instancia- ante el Juzgado Letrado de Trabajo de la Capital de $6^{\circ}$ Turno (en adelante; "el Tribunal de Primera Instancia"). El trabajador promovió demanda laboral contra UBER reclamando diversos rubros de naturaleza salarial.

En cuanto a los argumentos de fondo, el trabajador fundó la existencia de una relación laboral, en el hecho de que la demandada opera como intermediario en la "provisión de mano de obra o trabajo o de sus choferes para satisfacer las necesidades de transporte o de sus clientes o usuarios".

Por su parte, UBER sostuvo que no existe entre las partes un vínculo de trabajo subordinado sino un contrato de naturaleza comercial, mediante el cual la empresa brinda un servicio de tecnología.

En lo que nos interesa (los aspectos formales), la parte UBER planteó como defensa, la excepción de falta de jurisdicción e incompetencia de la justicia oficial, por existir en el contrato de trabajo celebrado entre el trabajador y la empresa demandada, una cláusula arbitral. En concreto, UBER argumentó en su escrito de contestación de demanda que, las partes acordaron resolver cualquier controversia de acuerdo a lo previsto en la cláusula 14 del Contrato, bajo el nombre de "Legislación aplicable" el "Arbitraje" como medio para dirimir los conflictos que se plantearon entre las partes.

UBER argumentó que, en virtud del contrato celebrado entre las partes, el conflicto debía ser resuelto mediante arbitraje con Sede en Ámsterdam. Invocó a estos efectos, la reciente jurisprudencia de la SCJ que fuera comentada en el apartado que antecede. 
El Tribunal de Primera Instancia, rechazó el excepcionamiento planteado por UBER, asumiendo competencia en el caso e ingresando a analizar el fondo del asunto, en función de los siguientes argumentos;

- Los Jueces Letrados de Trabajo son los que deben entender en los conflictos individuales de trabajo por su especialidad y la autonomía del Derecho Procesal Laboral;

- La garantía del acceso a la justicia del Estado como derecho humano fundamental, que viene a completar el panorama protector respecto del trabajador, establecido en el art. 53 de la Constitución de la República;

- Los conflictos individuales de trabajo a los que refiere el art. 2 de la ley $\mathrm{N}^{\circ} 18.572$ no se definen por la naturaleza dependiente o independiente del servicio prestado, sino por los sujetos interesados y los intereses en juego. En consecuencia, el debate acerca de la naturaleza del vínculo que se adiciona a la jurisdicción aplicable, no resulta obstáculo para la aplicación de la disposición citada. Se expresa en la sentencia que: "Basta que se trate de un conflicto individual sobre materia laboral para que el proceso laboral autónomo desplace la aplicabilidad del derecho procesal común...";

- No corresponde integrar la solución legal con el CGP, por cuanto existe una expresa previsión legal que regula la cuestión (art. 2 de la ley $N^{\circ}$ 18.572). Aún en el caso de que se entendiera que existe un vacío legal, la integración no podría realizarse en base a las reglas de los arts. 472 y ss. del CGP en tanto se enfrentan con los principios de protección e irrenunciabilidad que edifican el Derecho del Trabajo (art. 31 ley No 18.572)";

- Los procesos y reglas de procedimiento previstas por la ley $\mathrm{N}^{\circ} 18.572$ y su modificativa, no dejan espacio para la libertad de las partes a los efectos de convenir el procedimiento conforme surge de su constante tenor imperativo, y que;

- A pesar de que la Recomendación de OIT número 92 admite el arbitraje como mecanismo de solución de conflictos individuales de trabajo, la regla cede ante la existencia de una norma interna más favorable representada por el derecho interno que garantiza la jurisdicción del Estado.

Habiendo rechazado las excepciones opuestas, el Tribunal de Primera Instancia condenó a la empresa UBER, a abonarle a la parte actora, los rubros laborales reclamados con el alance desarrollado en la sentencia. Asimismo, se dispuso como condena de futuro, abonar los rubros acogidos, mientras permanezca incambiado el relacionamiento laboral entre las partes.

La empresa UBER, interpuso en tiempo y forma recurso de apelación, asumiendo competencia en segunda instancia el TAT $1^{\circ}$, pronunciándose sobre los agravios planteados en el recurso. En sentencia $N^{\circ} 12-111 / 2020$, el TAT $1^{\circ}$ confirmó la decisión de primera instancia. En concreto, el dispositivo de la sentencia que se comenta, establece que: "...la Sala integrada desestima el recurso de apelación confirmando la decisión de primera instancia en cuanto entendió inadmisible el arbitraje en el ordenamiento nacional como instrumento de solución de conflictos individuales de trabajo" (el destacado nos corresponde). 


\section{Los fundamentos de la resolución del TAT $1^{\circ}$}

Se analizan en este capítulo, los principales fundamentos utilizados por el TAT $1^{\circ}$ en la sentencia comentada, a saber; i) "el derecho humano de acceso efectivo a la jurisdicción de la justicia del Estado" y su carácter "irrenunciable"; ii) "el arbitraje supone la exclusión de las garantías de la justicia estatal"; iii) "la autonomía del Derecho del Trabajo" -primacía de la ley especial sobre la ley general-, y; iv) el modelo de contrato de trabajo de UBER, con una cláusula arbitral leonina.

Una cuestión a destacar, es que muchos de los razonamientos jurídicos expuestos por el TAT $1^{\circ}$, ya fueran esgrimidos en el año 2013 por este mismo Tribunal (con integración parcialmente diferente) ${ }^{16}$, en la Sentencia $\mathrm{N}^{\mathrm{o}} 12-448 / 2013 .{ }^{17}$ En la sentencia que comentamos, el TAT $1^{\circ}$ mantuvo y reafirmó la misma postura sostenida hace ya varios años.

Analizamos también, algunos fundamentos expresados por el Tribunal de Primera Instancia, que decidimos calificar a efectos de establecer un orden lógico en las temáticas analizadas, como: "argumentos adicionales". El motivo de su análisis, obedece a que dichos argumentos, fueron ulteriormente confirmados íntegramente por el TAT $1^{\circ}$ en la sentencia de segunda instancia que se comenta.

\subsection{La posición de los Ministros que integran la mayoría del TAT $1^{\circ}$.}

En el presente sub-apartado se verán los principales argumentos en que se fundaron los Sres. Ministros; Dres. Rosina Rossi, Julio Posada y Lina Fernández Lembo, quienes conformaron la mayoría para el dictado de la sentencia de segunda instancia y en virtud de los cuales, se confirmó la resolución judicial de primera instancia, en cuanto al rechazo de la excepción de falta de jurisdicción de la justicia ordinaria deducida por la empresa UBER.

Sin perjuicio de las coincidencias o discrepancias que puedan surgir al respecto de la postura asumida por los Sres. Ministros que integran la mayoría y/o respecto de la posición de la Ministro discorde, los argumentos ensayados en la sentencia -todos- han sido debidamente fundados, en base a silogismos fácticos y jurídicos coherentes, con recepción dogmática y jurisprudencial.

La lectura del capítulo "Considerando" de la sentencia, permite apreciar que los argumentos ensayados por los Sres. Ministros que integran la mayoría, son conjeturas extraídas en base a una interpretación hermenéutica del ordenamiento jurídico uruguayo en general, de fuente interna y supranacional.

\footnotetext{
16 La integración del TAT $1^{\circ}$ en el año 2013, fue conformada por los Dres. Doris Perla Morales, María Rosina Rossi, Julio Posada (la sentencia referida fue objeto de discordia parcial conformada por la Dra. Raquel Landeira).

17 En dicho fallo, el TAT $1^{\circ}$, expresó que: "en el ordenamiento nacional el acceso a la justicia del Estado constituye un derecho humano fundamental blindado desde su fuente de reconocimiento en el bloque de constitucionalidad de los derechos humanos (art. 8 del Pacto de San José de Costa Rica que se integra por el art. 72 de la Constitución; Reglas de Brasilia sobre acceso a la justicia de las personas en condición de vulnerabilidad, recogida en Acordada 7647 de la Suprema Corte de Justicia)" (cf. SCIA. Nº 12-448/2013, TAT 1' ${ }^{\circ}$ disponible en: Base de Jurisprudencia Nacional (BJN).
} 


\section{i) El acceso a la justicia "estatal" como un derecho humano fundamental e irrenunciable, integrante del bloque de constitucionalidad.}

Sostuvo el TAT1 ${ }^{\circ}$ en la sentencia que se comenta, que el Derecho del Trabajo, tutela un bien jurídico fundamental, que, por naturaleza, adquiere el carácter de "derecho humano". En consecuencia, en palabras del TAT $1^{\circ}$; "el lugar desde donde se debe juzgar un conflicto sobre trabajo realizado por una persona es el Derecho de los Derechos Humanos."

Los Sres. Ministros que integran la mayoría, señalan en la sentencia comentada, que: "el derecho de acceso a la justicia constituye un derecho del cuerpo iuris del Derecho de los Derechos Humanos que opera como garantía de efectiva realización de los derechos humanos...". Concluyendo que: "El derecho de acceso a la justicia del Estado es irrenunciable (el destacado nos corresponde).

La postura del $\mathrm{TAT}^{\circ}$ se fundamenta en múltiples disposiciones de fuente supranacional. En particular, los Sres. Ministros respaldan su posición en lo establecido en; a) los arts. 8 y 25.1 de la Convención Americana de Derechos Humanos (Pacto de San José de Costa Rica); b) el art. 10 de la Declaración Universal de Derechos Humanos; c) las Reglas de Brasilia sobre acceso a la justicia de las personas en condición de vulnerabilidad, recogida en Acordada 7647 de la Suprema Corte de Justicia (en adelante; "Las Reglas de Brasilia") y; d) el art. 2.3 del Pacto Internacional de Derechos Civiles y Políticos.

A pesar de tratarse de una sentencia fundada, diferimos en la interpretación que realiza el TAT $1^{\circ}$ y las conclusiones arribadas. Para nosotros, todas estas disposiciones consagran el "acceso a la justicia" como derecho humano fundamental e inherente a la personalidad humana que, por naturaleza es irrenunciable, pero ninguna de ellas impide que se pacte arbitraje para la resolución de conflictos individuales de trabajo. Veamos:

- La Convención Americana de Derechos Humanos (Pacto de San José de Costa Rica).

i) El artículo 8 del Pacto de San José de Costa Rica, establece -en lo medular- que:

"Toda persona tiene derecho a ser oída, con las debidas garantías y dentro de un plazo razonable, por un juez o tribunal competente, independiente e imparcial, establecido con anterioridad por la ley, en la sustanciación de cualquier acusación penal formulada contra ella, o para la determinación de sus derechos y obligaciones de orden civil, laboral, fiscal o de cualquier otro carácter" (el destacado y subrayado nos corresponde).

Lo primero que hay que destacar, es que los términos de; "tribunal competente, independiente e imparcial" (resaltado), no es exclusivo de la justicia oficial. Tampoco la cualidad de que la competencia de dicho tribunal sea "establecido con anterioridad por ley". En efecto, si consideramos la regulación establecida con carácter general en el CGP, es claro que el legislador autoriza a las partes la atribución de competencia a un tribunal arbitral, en sustitución del Juez natural. La jurisdicción arbitral, es reconocida por nuestra ley procesal y por el constituyente (cf. arts. 6 y 57 de la Carta).

Lo segundo a destacar, es que el contenido de la disposición refiere con un criterio amplio, a todas las materias -sin excepción o distinciones entre ellas- (subrayado). Ello reafirma nuestra interpretación, por cuanto si se entendiera que el derecho de "acceso a la justicia" consagrado en la norma, alude exclusivamente a la justicia estatal como derecho "irrenunciable" -y no a la justicia con carácter general; pública y privada-, dejaríamos por fuera del arbitraje, también otras cuestiones por ej. de naturaleza civil y comercial. 
En otras palabras, bajo el criterio sustentado por el TAT $1^{\circ}$, podríamos arribar a la conclusión de que, en ninguna de las hipótesis consagradas en la norma invocada, se podría renunciar a la justicia estatal para acudir al arbitraje en sustitución de la primera. Así entonces, el arbitraje como método alternativo de resolución de conflictos, perdería todo sentido.

A nuestro juicio, el artículo 8 del Pacto de San José de Costa Rica, consagra el derecho al acceso a la justicia en forma general, del mismo modo que lo hace la Constitución de la República (cf. art. 12), en base al principio de "Universalidad de acceso al proceso"18 y no el "derecho al acceso de la justicia del Estado", en términos estrictos como lo propone el TAT $1^{\circ}$. Entendemos, que el acceso a la justicia arbitral, también se vería comprendido bajo esta protección de carácter supranacional, independientemente de la materia que se trate.

ii) El artículo 25.1 del Pacto de San José de Costa Rica, establece bajo el acápite "Protección Judicial" lo siguiente:

"Toda persona tiene derecho a un recurso sencillo y rápido o a cualquier otro recurso efectivo ante los jueces o tribunales competentes, que la ampare contra actos que violen sus derechos fundamentales reconocidos por la Constitución, la ley o la presente Convención, aun cuando tal violación sea cometida por personas que actúen en ejercicio de sus funciones oficiales" (el destacado nos corresponde).

Una lectura superficial de la norma, nos llevaría a concluir -erróneamente-, por la terminología empleada en su acápite ("protección judicial"), que la disposición se vincula -únicamente- con la justicia oficial, propia del Poder Judicial. Sin embargo, su contenido tiene más bien un sentido general y abarcativo, que nos permite ampliar el alcance conceptual de "justicia" que lo subyace, a cualquier otro mecanismo de administración de justicia, no necesariamente público, sino también privado.

En el fondo, la norma tiene un contenido similar al art. 8 mencionado precedentemente, con el agregado y énfasis especial, de la celeridad en la administración de justicia. Por cierto, este aspecto es un punto favorable al arbitraje con relación a la justicia oficial, si consideramos la estructura general de los procesos ordinarios (en el marco del CGP). En el caso de los procesos laborales (bajo la ley procesal uruguaya) y particularmente el proceso abreviado caracterizado por su rapidez, esta ventaja no se vería tan ostensiblemente, aun cuando en el arbitraje las partes pueden pactar la estructura procedimental y los tiempos aproximados del proceso.

\section{- Las Reglas de Brasilia sobre acceso a la justicia de las personas en condición de vulnerabilidad -recogida en la acordada 7647 de la SCJ-.}

Particular mención merece las Reglas de Brasilia, que fueran también invocadas -en forma general- por el TAT $1^{\circ}$, como fundamento de la sentencia comentada.

Al respecto, en la "Sección 5", bajo el acápite: "Medios alternativos de resolución de conflictos", las Reglas de Brasilia establecen en su artículo 43, que: "Se impulsarán las

18 Sobre este principio señala el Prof. Gabriel Valentin que: “...toda persona tiene derecho a acceder a un órgano jurisdiccional para la tutela de sus derechos subjetivos e intereses legítimos, cuando se afirma que estos derechos o intereses fueron desconocidos o violados. En definitiva, es el derecho que tiene cualquier persona de acceder al tribunal para la eliminación de su insatisfacción jurídica. Este principio tiene dos dimensiones: la universalidad del acceso en sentido subjetivo (todas las personas pueden acceder al tribunal) y en sentido objetivo (todas las pretensiones jurídicamente posibles pueden ser propuestas al tribunal)" (Valentín, 2017). 
formas alternativas de resolución de conflictos en aquellos supuestos en los que resulte apropiado, tanto antes del inicio del proceso como durante la tramitación del mismo. La mediación, la conciliación, el arbitraje y otros medios que no impliquen la resolución del conflicto por un tribunal, pueden contribuir a mejorar las condiciones de acceso a la justicia de determinados grupos de personas en condición de vulnerabilidad, así como a descongestionar el funcionamiento de los servicios formales de justicia" (el destacado nos corresponde).

Seguidamente, el artículo 44 de las Reglas de Brasilia establece que: "En todo caso, antes de iniciar la utilización de una forma alternativa en un conflicto concreto, se tomarán en consideración las circunstancias particulares de cada una de las personas afectadas, especialmente si se encuentran en alguna de las condiciones o situaciones de vulnerabilidad contempladas en estas Reglas. Se fomentará la capacitación de los mediadores, árbitros y otras personas que intervengan en la resolución del conflicto."

El espíritu de las Reglas de Brasilia es claro. Se procura no limitar el derecho de "acceso a la justicia", únicamente a la estatal, sino ampliar el elenco de mecanismos de resolución y disolución de conflictos (por autocomposición y heterocomposición), considerando especialmente la situación de vulnerabilidad de los sujetos intervinientes. Quedará entonces, sujeto a la voluntad de las partes, acudir a la justicia estatal o a la justicia privada, para resolver sus conflictos y alcanzar la satisfacción jurídica. Empero, limitar el acceso a la justicia, únicamente a la proveniente del Estado, calificado como "irrenunciable", -entendemos- es perjudicial para cualquier justiciable y no se ajusta a la normativa supranacional aprobada por nuestro país.

\section{- La Declaración Universal de Derechos Humanos.}

El artículo 10 de la Declaración Universal de Derechos Humanos, establece que: "Toda persona tiene derecho, en condiciones de plena igualdad, a ser oída públicamente y con justicia por un tribunal independiente e imparcial, para la determinación de sus derechos y obligaciones o para el examen de cualquier acusación contra ella en materia penal."

La norma transcripta no merece un mayor análisis. No vemos aquí una limitación -mucho menos una prohibición- para acudir al arbitraje a los efectos de resolver los conflictos individuales de trabajo. En concreto, la norma consagra con carácter general y sin distinción, el "acceso a la justicia" como derecho humano fundamental. Sobre el particular, nos remitimos "breviatis causae", a las consideraciones ya efectuadas precedentemente.

\section{- El Pacto Internacional de Derechos Civiles y Políticos.}

El artículo 2.3 del Pacto Internacional de Derechos Civiles y Políticos, establece que: "Cada uno de los Estados Partes en el presente Pacto se compromete a garantizar que: a) Toda persona cuyos derechos o libertades reconocidos en el presente Pacto hayan sido violados podrá interponer un recurso efectivo, aun cuando tal violación hubiera sido cometida por personas que actuaban en ejercicio de sus funciones oficiales; $b$ ) La autoridad competente, judicial, administrativa o legislativa, o cualquiera otra autoridad competente prevista por el sistema legal del Estado, decidirá sobre los derechos de toda persona que interponga tal recurso, y desarrollará las 
posibilidades de recurso judicial; c) Las autoridades competentes cumplirán toda decisión en que se haya estimado procedente el recurso" (el destacado nos corresponde).

La norma en cuestión tampoco constituye un obstáculo para el arbitraje. Por el contrario, se destaca una clara disyuntiva que amplía el elenco de mecanismos "oficiales" y alternativos posibles para alcanzar la satisfacción jurídica, siempre que se encuentre prevista en el sistema legal del Estado. Como dijimos, el proceso arbitral se encuentra expresamente regulado en el CGP (arbitraje doméstico), en la LACI (arbitraje comercial internacional), y también es reconocido en la Constitución de la República.

De acuerdo al escenario planteado, entendemos que conforme a la regulación supranacional invocada por el TAT $1^{\circ}$, no habría mayores obstáculos para acudir a arbitraje si así lo convienen las partes en ejercicio de su autonomía de la voluntad. No hay dudas de que, el acceso a la justicia es un derecho humano irrenunciable, pero el mismo no se restringe a la justicia estatal sino a los diferentes sistemas de administración de justicia en general. El arbitraje no limita el derecho de acceso a la justicia, sino que, por el contrario, amplia el elenco de mecanismos de resolución de conflictos posibles. Este es el espíritu de la normativa aplicable de fuente legal (interno y supranacional) y constitucional.

Para nosotros, la cuestión a resolver no se trata de la exclusión de la garantía del acceso a la justicia estatal, sino de ponderar las garantías que ofrece el arbitraje a los justiciables, los mecanismos que pudieran surgir para mitigar su onerosidad, y la idea de especialidad y autonomía del derecho procesal laboral con relación a la regulación general establecida en el CGP.

Así, también lo expresó el propio TAT $1^{\circ}$ en un pasaje de la sentencia, en los siguientes términos: “...el problema a resolver se sitúa (...) concretamente en el instrumento procesal aplicable y en tal sentido si el arbitraje reporta las mismas garantías y facilidades de acceso que la justicia de los órganos estatales".

\section{ii) ¿E1 arbitraje supone la exclusión de las garantías de la justicia estatal?}

El TAT ${ }^{\circ} 1$ fundamenta su decisión, en base al argumento de que el arbitraje como método alternativo de resolución de conflictos, excluye a la jurisdicción estatal, y con ello, también se excluyen los derechos y garantías que ofrece en la actualidad el proceso laboral establecido en la Ley $\mathrm{N}^{\mathrm{o}} 18.572$ y modificativas.

Para el TAT $1^{\circ}$, al acudir a la justicia arbitral, se estaría excluyendo la garantía de una justicia orgánicamente especializada y el elenco de derechos y garantías que consagran la desigualdad compensatoria que tiende a garantizar el acceso a la justicia, y -como derivado del principio protector; "indubio pro operario"-, la gratuidad de las actuaciones judiciales en beneficio del trabajador que se encuentra en una situación de vulnerabilidad frente a su empleador. Los derechos y garantías enunciados son -para el TAT $1^{\circ}$ - consecuencia de un Derecho Procesal del Trabajo autónomo e independiente del Derecho Procesal común y su regulación general. Analizamos a continuación, cada uno de los argumentos mencionados. 
- La Autonomía del "Derecho Procesal Laboral", la inaplicabilidad del CGP por vías de integración y la garantía de una justicia orgánicamente especializada.

En apretada síntesis, el TAT $1^{\circ}$ sostiene en su sentencia que, tratándose el "Derecho Procesal Laboral" de una disciplina jurídica especial y autónoma, no resulta aplicable la regulación que, con carácter general, consagra el CGP respecto del proceso arbitral, en base al mecanismo de integración establecido en el artículo 31 de la Ley $\mathrm{N}^{\mathrm{o}} 18.572 .{ }^{19}$

A criterio del TAT $1^{\circ}$, la regulación del proceso arbitral establecida en el CGP es contraria a los principios sustantivos del Derecho del Trabajo y en consecuencia, su aplicación -por vía de integración- es inadmisible.

En efecto, argumenta el TAT $1^{\circ}$ que: "la aplicación supletoria del derecho procesal común concretamente del art. 472 del CGP que invoca la recurrente resulta inadmisible por cuanto no sortea el test de compatibilidad con los principios procesales especiales, los principios y reglas del bloque de constitucionalidad y los principios sustantivos del Derecho del Trabajo. La razón más elocuente reside en la colisión insalvable con los principios de gratuidad e irrenunciabilidad de las garantías procesales especiales". Finalmente, concluye el TAT $1^{\circ}$ que: "no corresponde empezar a razonar el punto en debate por el art. 472 del C.G.P. sino por la Ley especial que disciplina el orden y formalidades de los juicios".

\section{- Sobre la autonomía del Derecho Procesal del Trabajo.}

La cuestión no es menor y ha sido objeto de un extenso debate que mantiene enfrentada a la doctrina laboralista -que califica mayormente al "Derecho Procesal Laboral" como una disciplina autónoma-, y la procesalista - sostiene lo contrario, partiendo del concepto de "unidad del Derecho Procesal"-. Veamos, cada una de las posiciones dogmáticas señaladas.

a) La posición de la dogmática procesalista.

Gran parte de la doctrina procesalista, -impulsada por ARLAS, J.- considera que el Derecho Procesal es uno solo, con independencia de las especialidades derivadas de la materia objeto de la pretensión y las reglas procesales específicas aplicables a cada una de las distintas ramas del Derecho Procesal. Ello, por cuanto en el Derecho Procesal rigen principios y reglas comunes para todos los tipos de procesos jurisdiccionales, que son compatibles con las distintas "ramas procesales" y con la especialización de los distintos sectores judiciales.

Más recientemente, el Prof. Abal Oliú (2020), A. expresó que:

no hay muchos derechos procesales, existe un único Derecho Procesal. En efecto, aquellos institutos, conceptos y principios generales especiales cuya existencia señalaba que fundaba la autonomía del Derecho Procesal, son aplicables a todo proceso, sin importar que el objeto de ese proceso concreto implique normas de Derecho Civil, o Penal, o Laboral, o Agrario, etc. (p. 16).

19 El artículo 31 de la Ley $\mathrm{N}^{\circ}$ 18.572, establece que: "Todo lo que no esté previsto en la presente ley se regirá por lo dispuesto en las disposiciones especiales en materia laboral y en el Código General del Proceso en cuanto sea aplicable, se ajuste a lo dispuesto en los artículos $1^{\circ}$ y 30 de esta ley y no contradiga los principios del Derecho del Trabajo." 
Agrega el autor, que:

(...) la materia (el sector del Derecho Sustantivo) a la cual refiere el objeto de cada proceso, a menudo exige alguna regulación especial correspondiente al proceso. Más aun cuando estas especialidades ocasionalmente deban establecerse, ellas no justifican en forma alguna una conclusión que permita hablar, con propiedad, de la existencia de varios derechos procesales autónomos (Derecho Procesal Civil, Penal, Laboral, etc.), sino, a lo más, de la existencia de algunas especiales (o de algunas especialidades) dentro de un único Derecho Procesal (Abal Oliú, 2020, pág. 16).

Por su parte, el Prof. Pereira Campos, ha expresado su opinión, señalando (con particular énfasis a la temática objeto de estudio en este trabajo) que:

...resultan aplicables al arbitraje en materia laboral las normas que el Código General del Proceso (CGP) contiene en materia de proceso arbitral (Título VIII Libro II) -arts. 472 a 507-, dada la notoria vocación de generalidad de dicho cuerpo normativo abarcando los procesos (arbitrales y oficiales) de todas las materias, salvo excepción expresa, que no existe en materia laboral. Ello surge claramente de su exposición de Motivos y de los antecedentes parlamentarios, la aplicación del CGP al proceso arbitral laboral, se ve incluso ratificada por la previsión del art. 472 que refiere a "toda contienda individual o colectiva”, admitiendo en ambos casos el arbitraje (Pereira Campos, 1995, pág. 414).

Esta posición fue recogida y plasmada por el legislador en la exposición de motivos del CGP. Señala la Prof. -laboralista- Mangarelli, que:

en la exposición de motivos del Anteproyecto del Código General del Proceso suscrito por Gelsi, Torello y Véscovi, se hace referencia a los principios que se recogen (oralidad, inmediación, concentración, publicidad) sosteniéndose que, si bien estos principios han sido reclamados para los procesos que refieren a materia de importancia social, el Código los establece para todos los procesos" (Mangarelli, 2005, pág. 43).

Agrega además la autora que:

en dicha exposición de motivos se señala la postura en la que se basa el Código con relación al Derecho Procesal como disciplina, sosteniendo que existe una ciencia procesal, y solo se admiten "variantes mínimas" en el proceso, en función de la materia a la que refiere. La referida posición no parece admitir la existencia de un Derecho Procesal del Trabajo autónomo, ni aun especial (Mangarelli, 2005, pág. 43).

b) La posición de la dogmática laboralista.

Por su parte, la doctrina laboralista postula la idea de que el Derecho Procesal del Trabajo es una disciplina jurídica autónoma y no una mera especialidad que se distingue del Derecho Procesal común.

Al respecto, se destaca la posición de la Ministro ROSSI R, que ha sostenido que los principios constitucionales de acceso a la justicia (art. 12 de la Carta), legalidad (art. 18 
de la Carta) y el principio protector (art. 53 de la Carta), “...determinaron que el legislador cumpliendo el con el mandato constitucional pendiente elaborara (...) un sistema laboral procesal autónomo del derecho procesal común y a medida del conjunto de todas tales garantías constitucionales" (Rossi, 2011, pág. 296).

Entendemos, que las dos primeras referencias constitucionales realizadas por la Ministro, son también aplicables con carácter al proceso civil -en sentido amplio-. En cuanto al principio protector, entendemos que se trata de una especialidad derivada de la naturaleza de la pretensión tramitada en el proceso laboral y que se encuentra también recogido en el artículo 350 del CGP inc. 3ro y 5to.

La Prof. Mangarelli, también se ha pronunciado a favor de la autonomía del proceso laboral, en los siguientes términos:

...el derecho procesal del trabajo constituye una disciplina autónoma dado que refiere a una materia extensa y cuenta con principios, institutos y desarrollos propios. La circunstancia de que el proceso laboral comparta con el proceso común algunos principios, no impide ni debilita la autonomía del proceso laboral (Mangarelli, 2005, pág. 43).

\section{Continua la autora diciendo que:}

la autonomía del derecho procesal del trabajo y del proceso laboral no se han visto afectadas con la aprobación del Código General del Proceso...la autonomía del proceso laboral se funda en la particularidad que le impone el derecho laboral sustancial y los principios del proceso laboral (p. 43).

Para nosotros, el Derecho Procesal es uno sólo (el proceso laboral pertenece a un tronco común) y la regulación general establecida en el CGP, tampoco contradice los principios y reglas del Derecho del Trabajo -sustantivo-. Como hemos dicho, el legislador se ha preocupado por contemplar especialmente la especialidad de la pretensión en el artículo 350 del CGP. En cuanto a los principios sustantivos del Derecho del Trabajo, entendemos que los mismos son también aplicables en el arbitraje.

Coincidimos con los fundamentos de la SCJ en cuanto a que:

la sujeción al arbitraje no supone jamás la abdicación por parte del trabajador a las garantías (protección) que emanan de la normativa y de los principios del derecho laboral. Por el contrario, un proceso arbitral en el cual se resuelva una cuestión relativa a un conflicto individual de trabajo, deberá ajustarse a las normas y principios del derecho del trabajo, por lo cual no se advierte incompatibilidad alguna.

\section{- Sobre la garantía de una justicia orgánicamente especializada.}

Sostiene el TAT $1^{\circ}$ que: “... la función jurisdiccional en materia de conflictos individuales de trabajo del hombre bajo cualquier forma contractual, estaría reservada a los tribunales de justicia con competencia en conflictos individuales de trabajo". 
Se agrega además en la sentencia que: "el Poder Judicial como integrante del Estado cumple la función de garantizar los derechos fundamentales de las personas, por lo que la suya es la jurisdicción natural para atenderlos."

Concluyen los Sres. Ministros -integrantes de la mayoría- que:

por el fundamento que viene de explicitarse, la jurisdicción para resolver el conflicto de materia laboral ha sido resuelta de manera excluyente en favor de la justicia del Estado y mediante las estructuras procesales previstas por la ley 18572 o por las especiales de la materia (...) de allí, que la inexistencia de previsión del arbitraje no constituye una laguna, sino que responde a una decisión expresa del ordenamiento jurídico especial nacional.

En forma coadyuvante con la posición del TAT 1ㅜㄹ la Ministro Rossi (integrante del Tribunal) expresó que:

...la jurisdicción consiste en la función pública realizada por los órganos competentes del Estado, con las formas requeridas por la ley, en virtud de la cual, por acto de juicio, se determina el derecho de las partes, con el objeto de dirimir sus conflictos y controversias de relevancia jurídica, mediante decisiones con autoridad de cosa juzgada, y eventualmente factibles de ejecución. Es la actividad de dirimir conflictos y decidir controversias con autoridad de cosa juzgada y poder de coerción. Y la competencia es la medida de distribución de jurisdicción entre los órganos" (Rossi, 2011, pág. 296).

Sobre la posición del TAT $1^{\mathrm{o}}$ y las autoras mencionadas, corresponde realizar dos puntualizaciones concretas.

En primer lugar; existe una posición jurisprudencial fundada con recepción a nivel nacional y en el derecho comparado que discrepa con la naturaleza "no jurisdiccional" que el TAT $1^{\circ}$ le atribuye al arbitraje.

Algunos autores, sostienen que el sólo hecho de que el Tribunal arbitral no tenga poder de imperio para hacer ejecutar lo juzgado, no impide que el arbitraje-como mecanismo privado de administración de justicia- sea considerado jurisdiccional.

En este sentido, creemos sumamente aplicables al caso, las palabras del Prof. Barrios De Angelis, D. en tanto oportunamente expresó que el arbitraje es un “...proceso con órgano jurisdiccional privado". Agrega el autor, que: "el arbitraje, en cuanto proceso, es tan público como el proceso oficial o judicial, constituyendo una especie jurisdiccional. Su distintivo fundamental es la naturaleza privada del juzgador" (Barrios de Angelis, 1978, pág. 7).

Compartimos las afirmaciones realizadas por la Prof. De Hegedus en cuanto a que:

la función que desempeñan los árbitros en la resolución de los conflictos a ellos sometidos es de naturaleza jurisdiccional, de igual categoría a la que realiza la justicia oficial, se aplicarian todos los principios que defienden dicha actividad, destacando, especialmente el de independencia, imparcialidad, autoridad y responsabilidad (De Hegedus, 2008, pág. 434). ${ }^{20}$ 
Destacamos también, la posición de la SCJ en la sentencia N 596/2017, en la que-por mayoría debidamente integrada- señaló que la función jurisdiccional que desempeñan los árbitros, es de idéntica naturaleza y categoría que la ejercida por la justicia oficial.

En el Derecho comparado, Caivano (2006) ha analizado la cuestión en términos sumamente claros y explicativos, que debemos transcribir. Señala el autor argentino que:

La jurisdicción es un concepto con fuertes connotaciones públicas y generalmente asociado a la idea del Estado. Como este crea el Derecho y tiene el deber de asegurar el cumplimiento efectivo de las conductas impuestas por las normas, se razona que, si la función jurisdiccional interesa al conjunto de la sociedad, es lógico que se ejerza a través de los órganos del Estado. Concebido el ordenamiento jurídico como un medio de control social (pp. 107-153).

\section{Agrega Caivano que:}

...la jurisdicción presenta un doble carácter: público, en cuanto procura la actuación del Derecho cuando la norma no ha sido observada y el mantenimiento de la paz social, y privado, en tanto se propone también satisfacer intereses particulares de quienes están directamente involucrados en la situación de conflicto. En este último aspecto, no puede negarse a las partes el derecho de satisfacer los intereses particulares a través de métodos distintos del litigio judicial, lo cual ocurre, por ejemplo, cuando las partes emprenden negociaciones -en forma directa o con la asistencia de un mediador-con la intención de poner fin al conflicto a través de un acuerdo mutuamente satisfactorio. Las mismas razones pueden invocarse para fundar el derecho de las partes a pactar el arbitraje..." (Caivano, 2006, págs. 107-153).

A mayor abundamiento, señala el autor que:

aunque exista un interés público implícito en la noción de jurisdicción, esta no es -ni puede ser- una función exclusiva del Estado, ya que no puede suprimir el derecho de quienes, en la órbita de sus derechos disponibles, procuran una solución al conflicto por vías diferentes del sistema judicial. Ello, naturalmente, siempre que la resolución sea pacífica y no vulnere esenciales principios de convivencia, condiciones que cumple perfectamente el arbitraje. Existe una zona de libertad que permite a los particulares prestar un consentimiento válido para componer cierta clase de conflictos mediante un acuerdo directo o, en las mismas condiciones, sustraerlos de la esfera del Poder Judicial para someterlos a decisión de jueces árbitros. En la medida que sólo afecte intereses y derechos disponibles, la decisión de las partes de renunciar a ser juzgados por los órganos judiciales provistos por el Estado no puede producir agravio a la comunidad ni al orden jurídico, ya que satisface tanto los intereses particulares involucrados en la controversia, cuanto los públicos en obtener una solución pacífica" (Caivano, 2006, págs. 107-153).

\section{Concluye Caivano que:}

No cabe duda que los árbitros ejercen una función esencialmente jurisdiccional. Aun cuando carecen de "imperium", lo que define la esencia de la jurisdicción es la atribución 
cognoscitiva y decisoria, y el efecto que esta decisión tiene, independientemente de si el órgano que la dictó puede ejecutarla forzadamente por sí mismo o si debe recurrirse al auxilio de otro. Sin embargo, es evidente que la jurisdicción de los árbitros no es exactamente igual a la de los jueces (Caivano, 2006, págs. 107-153).

En Segundo lugar, en nuestra opinión, la existencia de una justicia orgánicamente especializada en material laboral, no es impedimento para acudir a arbitraje. Conforme expresamos más arriba -en este trabajo-, el mecanismo de atribución de competencia establecida en la Ley No 18.572 es similar a la Ley No 15.750 (Ley Orgánica de la Judicatura y la Organización de Tribunales), pero ello no es óbice para someter el conflicto a la decisión de un tribunal arbitral.

En esta dirección, se ha pronunciado la SCJ en la sentencia N 596/2017 -en mayoría-, expresando que:

...la norma procesal se limita a establecer cuáles son los juzgados competentes para entender en una determinada materia; empero, de ello, en forma alguna, puede extraerse que la solución legislativa impida a las partes someter sus conflictos a un tribunal arbitral. Véase que postular lo contrario implicaría desconocer la naturaleza misma del instituto, pues, el acuerdo de partes supone justamente...la renuncia a hacer valer ante la jurisdicción ordinaria (justicia laboral art. 2 de la Ley $\mathrm{N}^{\circ}$ 18.572) las pretensiones contenidas en dicha cláusula...Es así que, en último grado de análisis, la tesis defendida en la recurrencia conduciría a soluciones absurdas, dejando al proceso arbitral virtualmente sin aplicación, ya que, en todas las materias, el Ordenamiento Jurídico, al distribuir competencia, necesariamente fija un determinado tribunal para juzgar y ejecutar lo juzgado (Ley $\mathrm{N}^{\circ} 15.750$ ), sin que ello suponga un obstáculo para someter el conflicto a la decisión de un árbitro" (el destacado nos corresponde).

\section{- La gratuidad en el proceso laboral.}

A juicio del TAT $1^{\circ}$, aun cuando fuera posible la aplicación de la regulación establecida en el CGP, el proceso arbitral en materia laboral debería respetar los principios especiales del proceso laboral. Sin embargo, en palabras del TAT 10; "atendiendo a la realidad nacional, ello solo sería posible si se garantizara un sistema de arbitraje con un procedimiento sencillo, adecuado, eficaz y gratuito. Lo que hoy por hoy, claramente no existe".

Al respecto señala nuestra doctrina que este beneficio que se otorga al trabajador, permite que puedan "litigar sin erogación alguna durante el proceso, hasta la ejecución de la sentencia incluida". Conforme señala el Prof. Varela Méndez, de esta manera se asegura el acceso al proceso a quienes no pueden soportar su costo, "ya que de lo contrario se comprometería la defensa en juicio" por existir una desigualdad de las partes ab initio (Varela Mendez, 2010, pág. 63). La gratuidad como regla, actúa entonces como una forma de equilibrar las desigualdades existentes entre el trabajador y el empleador (Becerra, 2005, pág. 76).

Sin lugar a dudas, uno de los desafíos más difíciles que presenta el arbitraje en materia laboral, es lograr armonizar el principio de gratuidad -rector del Derecho del Trabajo- con el proceso arbitral, que se caracteriza por presentar costos elevados (Garino Podestá \& Tiscornia Algorta, 2017, págs. 101-108). 
No obstante, entendemos que esta regla no puede ser un obstáculo objetivo -aplicable como regla general- que impida acudir a arbitraje para resolver cualquier conflicto individual de trabajo. En todo caso, deberían buscarse alternativas eficientes para mitigar la onerosidad del proceso y evaluar las circunstancias de cada caso en particular. A estos efectos, podrían ser de gran utilidad las soluciones legales adoptadas en el Derecho comparado que fueran comentadas al comienzo de este trabajo. En particular, la legislación de la República de Perú.

\section{- El principio protector.}

El "principio protector" conforma la esencia de la especificidad del proceso laboral. La idea de un proceso laboral autónomo persigue la finalidad de garantizar "en la contienda judicial la realización de los derechos laborales, evitando que la particular protección que las normas materiales establece para el trabajador se diluya durante el desarrollo de la causa".

El principio protector y sus amplias proyecciones tiene como ha señalado la doctrina laboralista, base constitucional a partir de la incorporación en el art. 53 de la Constitución de la República que establece: "el trabajo está bajo la protección especial de la ley" (Plá Rodriguez, 2018).

Entre las formas en que se expresa el principio protector se destacan; a) la representación automática del trabajador; b) la posibilidad de modificar la pretensión inicial (art.350.3 del CGP); c) los poderes de instrucción acordados a los tribunales penales (art.350.5 del CGP); d) la exoneración del pago de tributos judiciales, entre otros (Raso Delgue, 2005, pág. 54).

La presencia del principio protector como directriz inquebrantable de la actuación jurisdiccional, es uno de los pilares en que se cimienta la decisión del TAT $1^{\circ}$. Ya hemos expresado nuestra postura -coincidente con la de la SCJ-, de que este principio -y demás aplicables al Derecho del Trabajo-, también es de plena aplicación en el arbitraje.

\section{iii) El modelo de contrato de UBER, con una cláusula arbitral leonina.}

No es objeto de este trabajo analizar en profundidad los argumentos sustanciales relativos a la naturaleza jurídica del modelo de contrato de UBER. Igualmente, nos interesa destacar que, el modelo de contrato utilizado por la empresa UBER fue calificado por el TAT $1^{\circ}$, como un contrato de adhesión. Similar discusión, fue sometida a la decisión de la Suprema Corte de Justicia de Canadá en un caso análogo al presente -que fuera ya comentado en los apartados iniciales de este trabajo-.

Al respecto, expresó el TAT $1^{\circ}$ que, no puede admitirse la renuncia a la jurisdicción de los órganos de justicia del Estado cuando la "adhesión a la cláusula arbitral ha sido adoptada por quien estaba en situación de buscar trabajo en una comunidad en la que el trabajo es un bien escaso".

Los factores que determinaron la posición del TAT $1^{\circ}$, se enfocaron en la falta de poder de negociación del trabajador durante la etapa de tratativas precontractual, así como durante toda la ejecución del contrato.

El hecho de que en la cláusula arbitral se pactara como lugar Sede del arbitraje, la ciudad de Amsterdam, a sabiendas de que el trabajador se domiciliaba en Uruguay, allí 
tenía su centro de vida y desarrollaba su actividad laboral para UBER, fue determinante para la decisión del TAT $1^{\circ}$. El trabajador no tenía libertad ni poder de negociación en las cláusulas del contrato y, por ende, -para el TAT $1^{\circ}$ - la cláusula arbitral es nula por falta de consentimiento jurídicamente válido.

\section{iii) Argumentos adicionales esgrimidos por el Tribunal de Primera Instancia y ratificados por el TAT $1^{\circ}$.}

En este apartado, analizamos algunos argumentos esgrimidos por el Tribunal de Primera Instancia, que fueran confirmados por el TAT $1^{\circ}$ en la sentencia de segunda instancia que se comenta y -entendemos- son relevantes de acuerdo al enfoque analítico de este trabajo.

Nos interesa destacar la posición del Tribunal de Primera Instancia y del TAT $1^{\circ}$ en cuanto a la aplicación de las recomendaciones de la Organización Internacional del Trabajo (en adelante; “OIT") en materia de arbitraje.

$\mathrm{Al}$ respecto, sobre la posibilidad de acudir al arbitraje para resolver los conflictos individuales de trabajo, la recomendación $\mathrm{N}^{\circ} 92$ de la OIT de 1951, en su numeral 6to y bajo el capítulo "II" titulado "Arbitraje Voluntario" establece que:

Si un conflicto ha sido sometido al arbitraje, con el consentimiento de todas las partes interesadas, para su solución final, debería estimularse a las partes para que se abstengan de recurrir a huelgas y a lockouts mientras dure el procedimiento de arbitraje y para que acepten el laudo arbitral.

Sobre su aplicación al caso concreto, el Tribunal de Primera Instancia expresó en su sentencia que: "no puede dejar de indicarse que a pesar de que la Recomendación de OIT número 92 admite el arbitraje como mecanismo de solución de conflictos individuales de trabajo, la regla cede ante la existencia de una norma interna más favorable representada por el derecho interno que garantiza la jurisdicción del Estado, conforme dispone el art. 19 numeral 18 de la Constitución" (cf. punto 10 de la sentencia de primera instancia-el destacado nos corresponde).

A diferencia de los convenios internacionales de elaborados por la OIT ratificados por nuestro país, sus recomendaciones no tienen carácter vinculante para los Estados. En esencia, son directrices o guías prácticas de naturaleza "saft law", que sirven para orientar la actuación de los Estados de acuerdo a los principios básicos del Derecho del Trabajo a nivel global (Servais, 2018, pág. 20).

Consecuentemente, no sería en principio aplicable el artículo 27 de la Convención de Viena sobre el Derecho de los Tratados, que establece en cuanto a la relación del Derecho interno y las normas de naturaleza supranacional, que: "una parte no podrá invocar las disposiciones de su derecho interno como justificación del incumplimiento de un tratado".

Desde esta óptica formal, la postura asumida por el Tribunal de Primea Instancia, entendemos es adecuada. El juez natural competente no se encuentra obligado a seguir las recomendaciones de la OIT en forma ineludible. 
En lo sustancial, el motivo fundante del apartamiento de la recomendación de la OIT, es la existencia de una "norma más favorable" en el Derecho interno, que garantiza la jurisdicción del Estado.

El criterio de "norma más favorable" empleado por el Tribunal de Primera Instancia es una referencia subjetiva que puede o no variar, en función de las circunstancias del caso concreto y la postura del Tribunal que entienda en el asunto.

Nótese que, ante un mismo y único supuesto de hecho (el conflicto individual de trabajo), el concepto de "norma favorable" podría -eventualmente- variar en función de si el trabajador (tutelado especialmente por el legislador uruguayo) desea o no resolver sus disputas mediante arbitraje.

De regla, lo habitual es que sea el empleador quién posee mayor interés en acudir al arbitraje y oponga respecto de la pretensión del trabajador en sede judicial, la excepción de falta de jurisdicción. Sin embargo, la realidad es siempre más rica que la teoría y, por ende, debemos contemplar también la hipótesis en la que sea el trabajador quién desea ir al arbitraje. Podría suscitarse, por ejemplo, un reclamo vinculado a una situación de despido por notoria mala conducta que, por los hechos que puedan ventilarse en el proceso, el trabajador tenga interés en que el proceso se tramite con la confidencialidad característica del arbitraje. En estos casos -de excepción-, la norma más favorable de acuerdo a su interés será aquella que recomienda y regula su funcionamiento.

Sin perjuicio de las distintas posturas que pudieran surgir acerca de si es o no adecuado, dejar librado al interés de una de las partes -el trabajador- la aplicación o no de una disposición -no vinculante- de la OIT, la posición del Tribunal de Primera Instancia y del TAT $1^{\circ} 1$, es clara; se procura tutelar especialmente el interés del trabajador por encima de cualquier otro interés en juego, máxime cuando el derecho tutelado se trata del acceso a la justicia.

\subsection{La posición de la ministro discorde}

Los argumentos esgrimidos por la Ministro discorde (Dra. Doris Morales), siguen la misma línea de los fundamentos planteados por la SCJ en la sentencia que se comentó en capítulos anteriores de este trabajo. Nos limitaremos ahora, a indicar los principales argumentos fundantes de la discordia, remitiéndonos en cuanto a su análisis a lo ya mencionado en el capítulo correspondiente.

En resumen, expresa la Ministro discorde que corresponde hacer lugar a la excepción de falta de jurisdicción planteada por la demandada, por cuanto los arts. 2 y 7 de la Ley $\mathrm{N}^{\mathrm{o}} 18.572$ no excluyen la posibilidad de someter los conflictos individuales de trabajo a un proceso arbitral. Posición que reafirma en base a lo dispuesto por el art. 476 del CGP, y el concepto de la materia laboral como una "materia transable".

Sobre el principio de "irrenunciabilidad", señaló la Ministro que, no se enfrenta al arbitraje por cuanto en éste deberán aplicarse los mismos principios sustantivos que rigen y orientan el Derecho del Trabajo en cualquier proceso jurisdiccional. Siguiendo la postura de la Dra. Landeira (Ex Ministro del Tribunal de Apelaciones de Trabajo de $2^{\circ}$ Turno) manifiesta que sería el propio Tribunal arbitral quien debe resolver acerca de la validez y eficacia de la cláusula arbitral -principio kompetenz kompetenz-. 
Concluye la Ministro discorde, que el artículo $2^{\circ}$ de la Ley $\mathrm{N}^{\mathrm{o}} 18.572$ es una norma distributiva de competencia, cuyo contenido se limita a establecer cuáles son los jueces competentes para entender en materia laboral. Al respecto, señala la Ministro que en todas las materias existen normas de atribución de competencia y no por ello el arbitraje resultaría inadmisible.

\section{Conclusiones}

Cuando la cuestión relativa a la arbitrabilidad objetiva de los conflictos individuales de trabajo en Uruguay parecía estar resuelta, con la posición debidamente fundada de la SCJ, el fallo del TAT $1^{\circ}$ pone nuevamente el tema en discusión.

En lo general, la posición del TAT $1^{\circ}$ es válida, la sentencia es congruente y debidamente fundada. Sin embargo, nos permitimos discrepar en algunas consideraciones jurídicas y conceptos técnicos procesales que, a la hora de aplicarlos en la práctica -para nosotrosdeberían tener una solución diferente a la señalada por el TAT $1^{\circ}$ en la Sentencia.

En este sentido, reafirmamos nuestra posición acerca de la unidad del Derecho Procesal. Para nosotros, no existe un Derecho Procesal del Trabajo autónomo y creemos, que de acuerdo al texto legal del artículo 31 de la Ley $N^{\circ} 18.572$, en todo lo que no esté regulado en dicha ley especial, deberá aplicarse el CGP -siempre que sea aplicable- por el mecanismo de integración normativa. Máxime, cuando el proceso arbitral regulado en el CGP no contradice los principios sustantivos y las reglas procesales especiales del proceso laboral. Estas reglas deberían aplicarse con el mismo tenor y alcance en el arbitraje. El único impedimento para considerar a una materia como "arbitrable" bajo la regulación del CGP, es su naturaleza "no transable" y en esencia el Derecho del Trabajo, es una materia disponible por los justiciables.

El principal impedimento para acudir al arbitraje en materia laboral lo constituye la máxima de gratuidad del proceso laboral. Sin embargo, no logramos compartir el criterio de que esta regla per se, impida -con carácter general- acudir al arbitraje en materia laboral. El desafío, será encontrar un mecanismo idóneo para mitigar la onerosidad del arbitraje para resolver este tipo de pretensiones, pero no creemos que la solución sea la inadmisibilidad del arbitraje como regla general.

En otro orden, compartimos con la Ministro discorde que el art. $2^{\circ}$ de la Ley 18.572 , es una norma atributiva de competencia y no tiene la finalidad de excluir al arbitraje como mecanismo alternativo de resolución de conflictos. Este argumento, implicaría que en todas aquellas materias que exista una norma de atribución de competencia, el conflicto no resultaría susceptible de ser resuelto mediante arbitraje, dejando a este método de resolución de disputas carente de todo sentido y utilidad.

En lo sustancial del caso concreto, compartimos la opinión del TAT $1^{\circ}$ en cuanto a la nulidad de la cláusula arbitral. El vicio de consentimiento del trabajador en el caso comentado es claro, y el modelo contractual utilizado por la empresa UBER contiene una cláusula arbitral leonina, que evidentemente no ha podido ser negociada por el trabajador. De lo contrario, no se explica por ej. que la sede del arbitraje sea la ciudad 
de Ámsterdam, cuando el trabajador desempeña sus actividades en Uruguay y es aquí donde tiene su centro de vida.

En definitiva, remarcamos la importancia de analizar al arbitraje a la luz del ordenamiento jurídico uruguayo, y encontrar soluciones en busca de lograr la armonía con las distintas materias de fondo. Ello, con la finalidad de que el arbitraje no implique una denegación de justicia, sino una opción adicional para el justiciable al momento de hacer valer sus derechos y resolver sus conflictos por el sistema de heterocomposición.

\section{Referencias bibliográficas}

Abal Oliú, A. (2020). Las normas que regulan el proceso jurisdiccional uruguayo: El Derecho Procesal Uruguayo. En A. ABAL OLIÚ, Manual de Derecho Procesal (pág. 16). Montevideo: FCU.

Barrios de Angelis, D. (1978). Manual del Arbitraje. Montevideo.

Barrios de Angelis, D. (1979). Teoría del Proceso. Buenos Aires: Depalma.

Becerra, R. (2005). El principio de ratuidad del proceso laboral. En Derecho Proceal del Trabajo-Treinta Estudios (pág. 76). Montevideo: FCU.

Caivano, R. (2006). Planteos de inconstitucionalidad en el arbitraje. Revista Peruana de Arbitraje $N^{\circ}$ 2/2006, 107-153.

De Hegedus, M. (2008). Autonomía de la cláusula arbitral, carácter jurisdiccional de la actividad arbitral. Revista Uruguaya de Derecho Procesal No 3-4/2008, 434.

Fernández Arroyo, D., \& VETULLI, E. (2020). The New Argentinian Arbitration Law. Kluber Arbitration Blog, 1.

Galindo Gil, P. (accedido en 2020). Ley de Arbitraje, Artículo 1 (Ambito de aplicación). Comentarios a la Ley de Arbitraje- Kluwer Arbitration Blog, 10.

Garino Podestá, J., \& Tiscornia Algorta, A. (2017). La Suprema Corte de Justicia Uruguaya reafirmó la arbitrabilidad objetiva de los conflictos invidiuales de trabajo. Revista de Derecho Procesal de la Asociación Iberoamericana de la Universidad de Salamanca $N^{o} 3,101-108$.

Garmendia, M. (1999). Arbitraje y acceso a la justicia del trabajo. Revista de Derecho Laboral Tomo XLII No 195, 599.

Heredia Cervantes, I. (2010). Validez de un convenio arbitral que implica la sumisión de un contrato internacional de trabajo a un tribunal arbitral con sede en el país del establecimiento del empresario. Revista de Arbitraje Comercial y de Inversiones- Kluwer Arbitration Blog, 2.

Higa García, A. (2016). Las cláusulas arbitrales y la Nueva Ley Procesal del Trabajo. Derecho \& Sociedad $N^{\circ} 46,309-306$. 
Mangarelli, C. (2005). La autonomía del Derecho Procesal del Trabajo y el Código General del Proceso. En Grupo de los Miércoles- Derecho Procesal del Trabajo- Treinta Estudios (pág. 43). Montevideo: FCU.

Olivera García, R., \& JIMENEZ DE ARECHAGA, M. (2000). El arbitraje en Uruguay. Centro de Conciliación y Arbitraje, Corte Internacional para el Mercosur, Bolsa de Comercio, 6-30.

Olivera Rangel, G., \& SARAVIA, D. (2018). El arbitraje en materia laboral: análisis de la sentencia de la suprema corte de justicia No 596/2017. Judicatura- Derecho Laboral $N^{o} 64,97$.

Pereira Campos, S. (1995). Los Laudos Arbitrales en Materia Laboral. En Treinta y Seis Trabajos Estudios sobre las Fuentas del Derecho del Trabajo (pág. 414). Montevideo: FCU.

Pereira Campos, S., \& SEINES, V. (2019). El Arbitraje Internacional en Uruguay Ley No 19636. CADE -Doctrina y Jurisprudencia-Tomo LII-Año 11, 5.

Pla Rodriguez, A. (1987). Curso de Derecho Laboral Tomo 1, Volumen 1. Montevideo: Idea.

Pla Rodriguez, A. (2018). Los principios del Derecho del Trabajo 3ra Ed. Monevideo: FCU.

RASO DELGUE, J. (2005). El principio protector en el proceso del trabajo. En Derecho Procesal del Trabajo- Treinta Estudios (pág. 54). Montevideo: FCU.

Rossi, R. (2011). Ambito de aplicación del nuevo sistema laboral procesal. Revista de la Facultad de Derecho No 31, 296.

Servais, J. M. (2018). Derecho Internacional del Trabajo y Resolución de Conflictos Laborales Transnacionales. Temas Laborales $N^{o}$ 144, 20.

Theoduloz Duarte, S. (2019). Arbitraj y Derecho de Familia ¿Una vìa posible de recomposición de conflictos familiares? En ANUARIO URUGUAYO DE DERECHO DE FAMILIA $T 7$ (pág. 156). Montevideo: FCU.

Valentin, G. (s.f.). Análisis de temas de Derecho Procesal- La vía de excepción para obtener la declaración de inconstitucionalidad de las leyes. Blog personal del autor-disponible en: https:/ /gabrielvalentin-derechoprocesal.blogspot.com/.

Varela Mendez, E. (2010). Principios aplicables a los proceso laborales. En Nuevas especialidades del Proceso sobre Materia Laboral (pág. 63). Montevideo: FCU. 